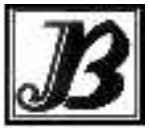

J. bio-sci. 21: 1-19, 2013

ISSN 1023-8654

http://www.banglajol.info/index.php/JBS/index

- Review Article

\title{
THE JAW TUMOR: A SURGICAL AND ONCOLOGIC PERSPECTIVE
}

\author{
M Badruddoja*, MD., FRCS. FRACS, FACS. FICS \\ Ex-Consultant Surgeon \\ Sherman and St Joseph Hospital, Elgin, Illinois \\ Royal Lancaster Hospital, University of Manchester, Lancaster, England \\ Director, Rehabilitation Associates of Illinois, Rockford, Illinois, USA
}

\begin{abstract}
The Jaw tumor is now a very well-known entity in the field of medicine and Called Burkitt Lymphoma Syndrome or Burkitt's lymphoma (BL). It is a highly aggressive non-Hodgkin's lymphoma and is the fastest growing tumors in children especially in East Africa. This is the first malignant extra nodal lymphoma in which Epstein-Barr virus has been detected specially in the tumors of East African origin The discovery of EBV is the Burk kit's tumor is another progress that has been MADE THE MEDICAL COMMUNITY to understand the disease process. EBV virus may be playing a role as an oncogene for this disease by retranslocating or translocation the C-MYC gene. Early days when such tumor is introduced by Dennis Burkitt before the medical community there was no real pathological classification, immumohistochemical or biological study. Subsequently it was felt that a chromosal translocation that activates an oncogene called e-MYC is the etiology of such tumor. But current molecular study shows that there are other oncogenes that are involved in the development of this deadly ailment especially in western countries. Our knowledge of BL was inadequate in early years of discovery of BL and so as well our diagnosis and treatment. In early stage of discovery of BL there were very limited option of treatment from local radical surgery, local radiation( which was not available in Uganda during that time) to only two chemotherapies and 5 years of survival rate was only $10 \%$.But with our current knowledge of molecular biology of this malignancy there are multiple options of treatment such as combination of various chemotherapies, monoclonal antibodies either alone and or in combination and with either complete removal of tumor or debunking procedure specially abdominal neoplasm, the current 5 years survival rate is about $90 \%$. This very brief review article describes the background, clinical feature, histology ,molecular study as it relates to prognosis and current treatment of both Burkitt's tumor and extra nodal abdominal tumor both based on experience of our group in late seventies of treating few cases of devastating abdominal $\mathrm{BL}$ and review of few scholarly article on $\mathrm{BL}$.
\end{abstract}

Key words: Burkitt, Burkitt lymphoma, oncogene c-MYC gene, the jaw and abdominal tumor, starry sky cell, gene mutation, monoclonal antibody, PET C scan, chemotherapy, surgery.

\section{Background of Burkitt lymphoma: the Jaw Tumor}

The story of discovery of Burkitt's lymphoma has a fascinating story. Dennis Burkitt is an Irish born and trained surgeon of Dublin, Ireland who lost the vision of one eye during a gang fight in his childhood. Even after losing one eye he was successful to become an excellent surgeon and is the discoverer of a lymphoma unknown in Uganda and currently such tumor is seen all over the world as sporadic form whereas the tumor in Uganda is endemic form. After completion of his medical training and passing the Fellowship examination of Royal College of Surgeons of Edinburg he joined he British Army as a surgeon during second world war II(1). He worked as a surgeon in early years of his life in various countries owned by British Raj including East Africans countries especially in Kampala, Uganda. .After tour of his duty in British Army Mr. Dennis

\footnotetext{
*Corresponding author E-mail: badruddoja@hotmail.com
} 
Burkitt feel in love with Kampala, Uganda and he returned to Kampala as a missionary surgeon and posted as a surgeon at Mulago Hospital, Kampala, Uganda in 1948 and as a lecturer in surgery at Makerere College Medical School. In 1957 one his colleagues asked him to see a boy with swelling of all quadrants of the jaws (2). A few weeks later he saw another patient with same findings in Jinja, on the northern coast of Victoria Nyanza. Burkitt was unsure of the diagnosis and made a comment 'we have seen children with one tumor but not like this in all quadrants of jaw". He took the child to Mulago Hospital and found that child has also has an abdominal tumor.

Burkitt knew he was onto something special "pivotal providence" he called it and this observation was ultimately change the direction of his medical career and became a pioneer in childhood cancer researcher in East Africa besides being a surgeon. He reviewed all the records of the patients with similar findings in Mulago Hospital, Kampala and found that such tumor is more common in children, but can affect any intra abdominal organs but sparing the peripheral lymph nodes. Each and every lesion contains small round blue cells. These cells did not look like lymphoma cells. Burkitt called few of his colleagues including Dr. George Oettle the pathologist in South African Institute of Medical Research, Johannesburg, South Africa. Dr. Oettle told that he has not seen such tumor in South Africa. Burkitt published these case reports of unusual tumor in Kampala, Uganda in British Journal of Surgery (3). This publication was practically unnoticed by medical community especially among the British surgeons, pathologist and oncologist. But this paper became a citation paper 25 years later. A later analysis showed that jaw involvement is in $100 \%$ cases and age related and such age is three years. But such tumor is less than $20 \%$ in teen age group. Median age is 7 years and more than $50 \%$ childhood tumor is jaw tumor in Uganda (4).

Three years later in 1961 Burkitt published an another paper describing the detail of the nature of the tumor in which it was found that the jaw and abdominal tumors are identical and is a type of lymphoma or sarcoma (5).In 1963, the Union for International Cancer control organization organized a symposium in Dakar, Senegal. But for political reason Dr. Oettle being a South African denied visa for Senegal. So the venue of the meeting changed to United Nations Educational, Scientific and Cultural organization building in Paris. During this session this lymphoma used to be called African Lymphoma or Childhood Lymphoma. A proposal was made by $50 \%$ of attendees that this tumor should be called Burkitt Lymphoma though all delegates felt that this growth is not atypical lymphoma and should not be called Burkittlymphoma (6). In recovery act it was discovered that Burkitt lymphoma makes excellent imprint preparations and has very characteristic cytological features of non-Hodgkin's Lymphoma, but differs morphologically from non-Hodgkin's Lymphoma (7).

The World Health Organization (WHO) convened a conference in Washington ton in 1967 to discuss about the nature of the Burkitt Lymphoma and its relationship to other lymphomas. It was felt that lymphoma should be diagnosed based on its morphology but not by clinical feature, and recent invention of immunehistochemistry has been used to support the diagnosis. Burkitt Lymphoma expresses B-cell markers: BL is CD 10 positive, CD20 positive and BC 12 negative. Proliferation markers show that $100 \%$ cells are in cycle. So it is a very rapidly growing tumor with rapid apoptosis with regeneration of new malignant cell. The hurdle is over and WHO has accepted that Burkitt lymphoma is a lymphoma and not a sarcoma as Burkitt thought in 1958. The current WHO classification of lymphomas includes two eponymous: Hodgkin's Lymphoma and Burkitt Lymphoma(8). Furthermore WHO (6) has classified Burkitt Lymphoma as follows:

A. Endemic Burkitt Lymphoma

B. Sporadic Burkitt Lymphoma

C. Immunodeficiency Associated Burkitt Lymphoma

D. B-Cell Lymphoma unclassifiable with features intermediate between large B-cell lymphoma and Burkitt Lymphoma. 
To celebrate the achievement of discovery of Jaw Tumor in Uganda 60 years ago and also to celebrate Denis Burkett's 100th birth day European Society of Hematology holds a conference in 2011 in Dublin, Ireland for three days. More than100 papers were present on Burkitt lymphoma. The participants were from all over the world.

\section{Epidemiology}

The epidemiology of this condition is very complex because of the fact that recent investigations on molecular study of Burkitt lymphoma shows that there are at last three kinds of Burkett's Lymphomas and each of them have different epidemiology. Dennis Burkitt after delivering his lecture on Burkitt Tumor (9) at Middlesex Hospital, London entitled Children's Cancer in Tropical Africa, he meet young virologist Epstein and his colleagues Barr. After the lecturer Epstein asked sample of the tumor as he is interested to know whether virus is responsible for this deadly disease especially in the time when chemotherapy is hardly available.

Epstin and his colleague got the sample from Uganda and was able to demonstrate the presence of virus particle in tumor tissue and since then it is called Epstein-Barr Virus (EPV) (10).Historically this is the first time a virus particle was found in a malignant neoplasm. On his return to Uganda Burkitt took a long safari in an old van of Ford to find out the epidemiology of this disease in Uganda. He took his colleague Edward Williams with him, traveled 10000 miles in 10 weeks and visited 53 hospitals (11).This trip virtually nailed down the area where such tumor is endemic. These areas are located in high rainfall with mosquito infestation area. He felt it is vector borne disease and this vector is Plasmodium falciparum. This area is Eastern part of Africa and incidence is highest in broad band extending some $10-15 \%$ on either side of the equator. It was originally felt such difference of incidence of $B L$ is due to altitude barrier. But incidence of $B L$ is also present in higher altitude above sea level area than low altitude area (12).Preachers at Entebbe Virus

Research Institute in Uganda observed that distribution of BL was very similar to other viral disease vectored by mosquito, therefore BL is caused by a virus vectored by insect (12). Similar findings are reported form New Guinea where incidence of BL is very high (13). Dalldorf et al. proposed in 1964 that malaria ,which is transmitted by female anopheles mosquitoes may be a better candidate for pathogenesis of disease since the distribution of $\mathrm{BL}$ not only correlate to the distribution of malaria ,but also to the intensity of malarial infection and subsequently they have confirmed this hypothesis by their laboratory research work(14). The distribution of endemic lymphoma across Africa and Papua New Guinea corresponds to areas of holoendemic malaria and the early acquisition of EBV infection (15).The annual incidence has been estimated at 40-50 per million children younger than 18 years (16).In these high risk areas endemic Burkitt's lymphoma comprises about half of all childhood cancer and up to $90 \%$ lymphoma diagnoses. Incidence picks at age 6 years and the diseases is twice as common in boys as in girls. These endemic BL in African children occurs between ages 4-7 years and male to female ration is 2:1 and involves jaw, other facial bones, nasopharyngeal area and also other thoracic and abdominal organs (17).

Mapping of the $\mathrm{BL}$ occurrence in East Africa shows a distinct geographic distribution in equatorial malaria infested areas with rain fall of more than 20 inches per year and an altitude of less than 5000 feet. Burkitt (18) has suggested that environmental factors, such as chronic malaria and parasitic infections may account for the host's susceptibility to the induction of neoplasia by some virus. It is possible that vector (mosquito/specially Plasmodium falciparum) bite may induce viremeia especially with EB virus. This causes dislocation of C-MYC gene which causes tumerogenesis of B-cell resulting in BL. The role of environment has been emphasized as an etiological factor in endemic Burkitt's lymphoma especially in East Africa. But precise significance of this factor is unknown special in Asia, Europe, North America and South America where scientist are working in the field of entomology, virology, and immunology. We treated ten patients in 
Midwest of United States (Iowa and Wisconsin) in children with Burkitt's lymphoma (19).The diagnostic criteria in all our 10 cases were based on the criteria of diagnosis established by WHO (20) and have occurred in mid-western part of united states in a climate characterized by an average altitude of 1,287 feet above sea level, 30 to 37 inches of rain fall per year, marked seasonal variation with extreme cold in winter with very hot summer. Also both lowa and Wisconsin are known as farming state without any risk factor of developing Burkitt's lymphoma which is prevalent in East Africa.

So further research is needed regarding the etiology of Burkitt's lymphoma. Lately there are reports of Burkett's lymphoma from various parts of United States of America, Europe, UK, Asia and Middle East. These areas are very low belt area of $B L$ and these are sporadic $B L$ area and the incidence is 2 per million in children younger than 18 years of age (21).Immune deficiency associated BL occurs at an incidence of 22 per 100000 people in USA (22). Another study shows that $40 \%-50 \%$ of pediatric lymphoma is Burkitt Lymphoma (23).

\section{Cyotogenetics of Burkitt lymphoma}

It is sometime difficult for cytopathologists to differentiate between Burkitt's lymphoma and large B-cell lymphoma. It is necessary to study gene expression /molecular study to differentiate between these two lymphomas. Burkitt's lymphoma is readily distinguishable by high level of c-MYC target gene, the expression of a subgroup of germinal center B-cell genes, and the low level of expression of major -histocompability complex class I genes and clear factor $-\mathrm{kB}$ target genes(24).These features are absent in large B-cell lymphoma. Such study is very important as far treatment is concerned for these two lymphomas. The normal function of C-MYC is enigmatic. But it is felt from recent laboratory investigations that central role of C-MYC gene is to control cell biology that includes cell proliferation, differentiation, metabolism, apoptosis and telomere maintenance.

The translocation of C-MYC gene has potential role in pathogenesis in Burkitt's lymphoma. This translocation of c-MYC gene may be caused by infection with EBV.70\%-80\% of patients with BL has translocation of $t(8$; 14) (q24; q32) and is the hall mark of Burkitt's lymphoma( 25).The variant translocations $t(2 ; 8)(p \quad 12 ; q 24)$ occurs in $10 \%-15 \% \mathrm{BL}(26)$. The molecular consequences of this three translocations is deregulated expression of the c-MYC oncogene which is an essential role in cell cycle control( 27).Deregulated expression arises as a result of juxtaposition of MYC to the enhancer elements of one of the immunoglobulin genes : the heavy chain at 14q32,the kappa light chain at 2p12 and the lambda light chain at 22q11.But these three have different break points.

Generally endemic BL has upstream MYC break point whereas sporadic BL has closer to MYC break point (28). The differences in MYC break points are probably due to differences in EBV positivity and between endemic and sporadic forms (29).Characteristic gene expression signature especially high level MYC secretion by BL signifies that this is a homogeneous disease (30). In $10 \%$ of $B L$ it has been found that there is no translocation involving the MYC gene. So it is possible that MYC gene might not be deregulated in these $10 \%$ cases of $B L$ and there may be other mechanisms (31).As these mechanisms in $10 \%$ case of $B L$ are unknown, all other features should be completely typical for diagnosis of BL.BL is invariably is associated with chromosomal translocation that deregulates over expression of c-MYC gene(32).

$B L$ has a simple karatotype with increasing genetic complexity linked to disease progression(33).Patient who had deletion of long arm chrosome 13 has worse prognosis compared to patients who does not have deletion of long arm chrosome 13(34). Over expression of c- MYC gene induces apoptosis through a p53dependant pathway in normal B-cells. Many BL have mutation of tumor suppresser gene which can override the cellular apoptotic machinery. A p53 independent pathway can be circumvented via down regulation of cellular protein BIM, which is an antagonist of the antiapoptotic protein (35). 
There are other multiple genes those are mutated in Burkitt lymphoma. Love and associates (36) have identified 37 genes that are mutated in BL including ID3, GNA13, RET, PIK3R1, SWI/SNF, ARID1A and SMARC4. This study shows that in the cancer for the first time including CCT6B, SALL3, FTCD and PC and ID3 mutation is present in $34 \%$ of $\mathrm{BL}$. This study also proves that ID3 is a new tumor suppressor gene. The study by Preudhomme et al. (37) shows that mutation of p53 has no effect on the prognosis of the patient. Richer et al. (38) found that cooperation between ID3 inactivating and IG-MYC translocation is a hall mark of Burkitt lymphogenesis.

The origin of Burkitt lymphoma is still controversial as to whether $B L$ lymphoma originates from $B$ germinal center cells or from memory B cells. Bellan et al. (39) did immunoglobin gene analysis by immunohistochemistry of Burkitt lymphoma. This study shows that all BL (endemic BL, sporadic BL, and AIDS -related BL) harbor mutated Vh genes with different mutation range among 3 types of BL. Endemeic $\mathrm{BL}$ and AID-related Burkitt's lymphoma has higher mutation rate than that of sporadic BL respectively (5.1\%,5.4\%and 1.5\% respectively). So it appears that EBV -positive BL and EBV-negative BL may originate from 2 distinct subset of $B$ - Cells, pointing to a particular role in the pathogenesis of this tumor.

The different types of C-MYC translocation reported in BL may also be related to the different stages of B-cell maturation. To the best of our knowledge this study represent largest series of BLS analyzed for a comparison of the cellular origin of endemic, sporadic, and AID related BL tumors cells and it may well reflect the situation in vivo. Indeed this study clearly demonstrate different cellular counterparts with significant implications for the pathogenesis of various types of BL. This. study tells that EBV -negative BL (sporadic) appears to drive from early centroblast and EBV -positive ( endemic BL and AIDS -related BL) originate from germinal center B cells or memory cells. But still it is not known whether such study has any therapeutic implication (40).Nearly all cases of BL have rearrangement of C-MYC oncogene with immunoglobulin heavy chain locus, leading to up-regulation of C- MYC expression by immunoglobulin enhancer elements.

\section{Clinical presentation}

The clinical presentation of $B L$ varies from types of the disease. Historically this tumor has been described as Jaw tumor by Burkitt $(2,41)$ which just discovered in East Africa. Of course few cases abdominal tumor have been described along with Burkitt lymphoma:" the jaw tumor". Swelling of jaw, orbit, nasophyrnx, tonsil may be the first presentation of endemic Burkitt lymphoma. This kind of presentation is very common in East Africa. A study in Malawian children showed that $31 \%$ presented with facial disease and $62 \%$ presented with abdominal disease (42) and peck age is 6-7 years of age. But most of the cases described in USA, Europe and rest of the world presents with sign symptoms of acute abdomen such as acute appendicitis, ovarian tumor, and intussusception (19).Sometimes it is absolutely difficult to diagnose BL when patient present with acute abdomen and initial diagnosis will be missed and patient is discharged from hospital after conservative treatment and diagnosed after laparotomy flowing recurrence of symptom of acute abdomen (43).60\%- $80 \%$ of patient with $\mathrm{BL}$ presents with symptoms of $\mathrm{BL}(44)$ which belongs to St. Jude stage III and IV.

lleocecal intusseption due to Burkitt's lymphoma has been reported as acute abdomen and initially treated conservatibily only to readmitted again with recurrence of symptom and diagnosis is established after laparotomy and bowel resection (45). Burkitt's lymphoma in adults accounts for $1 \%-5 \%$ of Lymphoma in USA and majority presents with extra nodal disease with abdominal symptoms either as chronic problem or as an acute problem. So patient presenting with abdominal problem a differential diagnosis of abdominal Burkitt's lymphoma should be kept in mind. The annual incidence of Burkitt lymphoma in North America is about 1200 per year and $59 \%$ are older than 59 and presentation of adult disease is mostly in abdomen and also mostly 
adult disease is associated with immunodeficiency disorder(46).Adults patients in general presents with rapidly growing diseases ,mostly with abdominal symptoms and extra nodal disease is common specially in bone marrow $70 \%$ and $30 \%$ in central nervous system.(47) An over view of three types of BL has been well described by Orem et al. (48) and is very instructive regarding the presentation of patients with three clinical types of Burkitt lymphoma ( Table1).

Table 1. An overview of clinical features of $B L$ clinical variants.

\begin{tabular}{|c|c|c|c|}
\hline Characteristics & e BL & $\mathrm{sBL}$ & HIV associated BL \\
\hline$\overline{\text { Clinical } \quad \mathrm{F}}$ & Facial skeleton (90\%) & Abdominal $80 \%$ & Organ and nodal \\
\hline Presentations & $\begin{array}{l}\text { Central Nervous system (33\%) } \\
\text { other organs are affected }\end{array}$ & Bone Marrow 20\% & Other Organs are affected \\
\hline $\begin{array}{l}\text { Pathologyl } \\
\text { Morphology }\end{array}$ & $\begin{array}{c}\text { Germinal cente } \\
\text { Monochromic medium with basophi }\end{array}$ & $\begin{array}{l}\text { 3-Cells } \\
\text { cytoplasm and multiple r }\end{array}$ & tic figures \\
\hline $\begin{array}{l}\text { Chromosomal } \\
\text { Translocation: }\end{array}$ & $\mathrm{t}(8 ; 14)$ (q24; q32) 60\%-70\%: t (8; 22 & (q24oq11), 10\%-15\%, t (2.8 & 12; q24):2\%-5\% \\
\hline Ig region involv & $\begin{array}{l}\text { ed: Ig heavy chain joining } \\
\text { (early B - Cell) }\end{array}$ & $\begin{array}{l}\text { Ig switch region } \\
\text { (Late stage B-Cells) }\end{array}$ & $\begin{array}{l}\text { Ig switch region } \\
\text { (Late stage B-Cells) }\end{array}$ \\
\hline EB Virus Assoc & ciation: $\quad 100 \%$ & $30 \%$ & $30 \%-50 \%$ \\
\hline Chemotherapy: & $\begin{array}{l}\text { Intensive chemotherapy } \\
\text { but currently in Africa low } \\
\text { low dose combinations are } \\
\text { given due to lack of supportive c }\end{array}$ & $\begin{array}{l}\text { Short Intensive } \\
\text { Chemotherapy }\end{array}$ & $\begin{array}{l}\text { Short Intensive } \\
\text { Chemotherapy }\end{array}$ \\
\hline Prognosis: & $\begin{array}{l}\text { Potentially very good prognosis } \\
\text { But compromised by poor health } \\
\text { System in Africa, social economic }\end{array}$ & $\begin{array}{l}\text { Very good } \\
\text { ctor }\end{array}$ & Very good \\
\hline
\end{tabular}

\section{Diagnosis}

All cases of Burikitt lymphoma of head and neck are diagnosed by biopsy. Open biopsy is much better technique than fine needle aspiration of biopsy. Open biopsy provides the pathologist adequate amount of tissue for both histochemistry and molecular study and such technique helps to chalk out an appropriate treatment plan (49). Laparotomy or laparoscopy will be required for the patients who presents with abdominal symptoms without any external evidence of tumor in jaw, head, neck, chest or other anatomical sites. Patients with this condition may undergo radiological diagnosis especially with CT scan. CT scan finding have been well described by Tesung et al. (50) and these findings are:

A. Tumor location predominantly in head, neck or in abdomen

B. Tumor is homogenous 
C. Margin is well localized distinct contrast from normal tissue

D. Extra nodal presentation of the tumor

E. Adjacent bone changes specially in head and neck area.

PET CT scan has high sensitivity with no false positive result in diagnosing BL especially in sporadic BL (51).However this endemic disease of underdeveloped countries like Uganda and other East African countries where PET/CT may not be available. So PET/CT is not an essential part of diagnostic technique or staging of the disease. Besides these diagnostic tests various other investigations are essential for purpose of treatment, prognosis and results of treatment. Patient should have complete blood count, blood CEA level, liver function test, ESR, coagulation profile, renal function specially GFR, serum lactate dehydrogenase, EBV virus status and chest $x$-ray. After confirmation of diagnosis bone marrow and cerebrospinal fluid (CSF) study should be done for the presence of malignancy (52).Presence of malignant cell in bone and or in CSF will help to stage the disease and treatment.

\section{Staging}

Staging of $B L$ should be done immediately once the diagnosis of $B L$ has been established as treatment should be commenced within 48 hours of diagnosis. Staging of any malignant disease is essential for purpose of treatment and this statement is also true for BL lymphoma as well. Various classifications have been proposed $(53,54)$. Currently Murphy/ St. Jude classification is used for children and Ann Arbor Classification is used for adult (Table 2).

Table 2. Staging system used in BL.

\section{Murphy System}

Stage I: Single Node or extra nodal site (Excluding mediastinum and abdomen)

Stage II: Two or more nodal areas on one side of diaphragm.

Stage IIR: Completely resected intra-abdominal disease

Stage III: Two or more nodal areas on opposite sides of diaphragm

or

Primary intrathoracic tumor

paraspinal or epidural tumor

extensive intra-abdominal disease

Stage III A: Localized non resectable abdominal disease

Stage IIIB: Widespread multiorgan intra-abdominal disease

Stage IV: Central nervous system or bone marrow Involvement

Favorable: Stage I and or IIR

\section{Ann Arbor System}

Single node or extranodal site

Two or more nodal areas on one side of diaphragm or localized involvement of extra lymphatic site and of one or more nodal sites on the same side of diaphragm

Two or more nodal areas on opposite diaphragm sides of the diaphragm which may and or include/involvement of spleen

or localized involvement of an extranodal

Diffuse or disseminated of one or more extralymphatic sites

Two single extranodal tumor on Opposite sides of diaphragm

Also $A+B$ depending on symptoms

Stage IA and IIA,

Stage I, II and III 
Murphy system takes account of frequent extra nodal disease with poor prognosis of intra-thoracic and intraabdominal disease. The Murphy system was evolved when surgery was frequent for both diagnosis and treatment and the entity of IIR. The systems differ in the way that a single extra-nodal site is categorized and that the Murphy system includes upgrading of non-resected intra-thoracic and intra-abdominal disease. The Murphy system also distinguishes central nervous system disease and bone marrow disease from other type of stage IV disease as defined in Ann Arbor system. In reality variable use of the different staging system in adults only makes a difference to the prognostic stratification and treatment offered to a minority of patients, but it does make the comparison of different series potentially more problematic. Staging is also important besides treatment and prognosis purpose as most of the Murphy/St. Jude classification patients belongs to children compared to adult patient who belongs to Ann Arbor classification. However the classification of BL in Uganda differs from that St Jud and Ann Arbor Classification.

Table 3. Uganda Classification of BL (55).

Stage A: Single extra-abdominal mass

Stage B: Multiple Extra-abdominal mass

Stage C: Abdominal mass with or without facial tumor

Stage D: Abdominal mass with sites of tumor other than facial and with bone marrow involvement

Stage AR: Abdominal tumor with more than $90 \%$ of tumor resected

\section{Pathological features}

The Burkitt tumor is a highly proliferating neoplasm originating from B cells. The proliferating index is almost $100 \%$ and doubling time is 12-24 hours (56). The morphologic features of all three varieties of Burkitt tumor endemic, sporadic and immunodeficiency variety are same except amount or number of EBV in the neoplastic cell. Almost all varieties are without peripheral lymphadenopathy, but if lymph node involvement is presents then limited to single group of nodes and this is very rare $(57,58)$. Bone marrow involvement is very common in late stage of the disease as described in the staging of the disease but leukemic manifestation is very rare $(59,46)$.Tumor is characterized my monomorphic ,medium size cell with diffuse pattern ,but in early stage shows preferential involvement of the germinal center(60).

The nuclei are round and have prominent basophilic nucleoli. The chromatin is coarse with thick nuclear membrane. The fat containing vacuoles are present and easily identified by touch preparation techniques. There is prolific mitosis and a prominent starry sky pattern is the rule, although not pathognomonic (61).There are plenty aptotic bodies in the cell. In well-fixed material the cytoplasm of each cell "squares off" forming acute angle in which membranes of adjacent cells abut on each other. Sometimes tumor shows granulomatous reaction (62).

Ultra structurally the main features are abundant ribosome, frequent lipid inclusion body, lack of glycogenparticlesand presence of nuclear pockets (63). Two morphologic variants of $\mathrm{BL}$ is present(64): $\mathrm{A}$. Plasmatoid differentiation and is common in HIV patient with eccentric basophilc nucleoli, B. Atypical or pleomorphic form ,cells are large. Phagocytosis of nuclear debris by reactive histocytes is as common as in 
the classic form resulting in a starry sky appearance (19). Since Burkitt tumor cell are of B-cell lineage and so tumor expresses immunoglobulin (IgM), invariably associated with heavy chain and light chain restriction (65).B-cell specific antigen CD19, CD20, CD22 and B -cell associated antigen CD24 and HLA-DR are present. Most cases also express germinal center cell markers CD10 and BCL16 (66).

Burkitt tumor is negative for activation marker $\mathrm{CD} 25$ and CD30.The most helpful immunohistochemical study for diagnosis for BL includes CD20+,CD10+,BCL2- and a Ki67 index over $85 \%$.All probability BL is a Blineage neoplasm and that is why shows clonal rearrangement of immunoglobulin gens. Because of this rearrangement of immunoglobulin genes MYC gene over expressed, promoting cell cycle progression and inhibiting differentiation (67).However translocation of MYC gene is not absolute diagnostic criteria for diagnosis of $\mathrm{BL}$ as increase of expression of MYC gene may occur in otherlymphomas. Gene expression profile has recently been shown the best technology to diagnose BL than any other current technology available and without use of this technology some expert in this field may miss the diagnosis(24).So whenever pathologist is in doubt on H\&E stain then gene expression study should be done. However again in underdeveloped countries such technique may not be available or may be very expensive. Currently if cytogenetic data are not available then FISH study studies are most helpful for supporting the diagnosis of $\mathrm{BL}$ especially when morphology is not classic and in adults, to demonstrate presence of MYC gene translocation together with absence of BCL2 and BCL6 translocation (66). The role of EBV for developing Burkitt Lymphoma is controversial as $100 \%$ of all patients with $\mathrm{BL}$ do not harbor $\mathrm{EBV}(68)$.

\section{Current modalities on treatment}

Historically at the time of the discovery of this unusual lymphoma which has been diagnosed as a jaw sarcoma by Burkitt, it was felt by Burkitt (2) that probably surgery is the treatment of choice for this condition. He did surgery in quite a few of his patients. He could follow few of his patients and found that there is recurrence of the tumor. He also felt that alternative treatment is radiation. But during that time radiotherapy was not available in Uganda. He referred one patient of Indian origin to Mumbai, India for radiation. Patient had radiation treatment of jaw tumor; she returned to Kampala and expired five months after radiation due to recurrence of the disease. With these experiences Burkitt felt that this disease is a systemic disease and felt chemotherapy is the choice of treatment. But at that time chemotherapy was not available in East African countries. In October 1960 Joe Burchenal a renowned oncologist for Sloane Kettering Memorial Hospital of New York was in Nairobi (3). He visited Burkitt at Mulago Hospital at Kampala. They treated the first patient with BL with Methotrexate at Burkitt's house and found dramatic response with such treatment. Since then Burkitt treated multiple patients with various chemotherapeutic agents such as methotrexate, cyclophosphamide and vincristine (69).

Burkitt have used small dose of chemotherapy for a very short period of time may be one or two doses and most of his patients responded. He felt that high dose of chemotherapy will destroy the immune system and body will not be able to prevent the regrowth of the neoplasm. It is quite logical that destruction of immune system of the body will not only will enhance the growth of malignant disease and also will cause nonmalignant disease as well. This event of 1960 opened the door for the chemotherapists of all over the world for further research for treatment of Burkitt lymphoma with various chemotherapies, monoclonal antibodies and creation of various protocol of treatment in various countries including East Africa where disease is endemic.

BL lymphoma should be treated immediately as soon as diagnosis is established as doubling time of $B L$ is 12-24 hours and proliferation index is $100 \%(56)$ and this suggests that this potentially curable disease should be considered as medico surgical emergency. All malignant diseases must be staged before initiation of treatment and this and this is also absolutely true for BL. Overall Survival (OS) rate, disease free survival 
(DFS) rate, complete remission rate (CR) and event free survival rate (EF) survival rate is almost $100 \%$ in stage I and stage ii Burkitt lymphoma provided appropriate treatment is started as soon as diagnosis and stage of the disease have been established. It is generally accepted that stage I and stage ii disease should have complete resection of the tumor, or debunking produce or cytreductive procedure followed by very short course of chemotherapy. Such method of treatment will result in 100\% five years DF survival and OSR (19, 70 , and 75). It is obvious that cytoredactive surgery will reduce the tumor burden and there by the intensity of adjuvant treatment will be less with less toxic effect compared to standard dose of adjuvant treatment. Others feel that BL is highly chemo sensitive tumor and so there is no need for surgery at all (71). However this is a matter of clinical judgment based on the circumstances and experience of the operating surgeon.

The biological behavior of endemic $B L$, sporadic $B L$ and immunodeficiency $B L$ are different and as such treatment also differs. Endemic $\mathrm{BL}$ is prevalent in Uganda and East Africa and treatment protocol differs from the European, North American and Asian countries.

According to Uganda protocol $\mathrm{BL}$ can be treated by surgery, chemotherapy, radiotherapy and immunotherapy (55).According to this protocol surgery has a definite role in tropical Africa. In tropical Africa the first doctor to encounter this ailment is usually a surgeon as patient presents with growth in thyroid, breast testis or abdominal tumor. The diagnosis very often require biopsy which because of rapid growth of tumor must be done within 24 hours of admission into the hospital. The biopsy sample if taken from jaw then biopsy sample should be done from inside the mouth especially in girls to avoid postoperative scaring. The second function of surgery is to reduce the tumor burden especially when patient presents with abdominal mass.

Cytoreductive surgery will require less intensive adjuvant treatment. If surgeon cannot remove $90 \%$ or more of the tumor then only biopsy should be done. Removal of tumor less than $90 \%$ does not alter the prognosis (72).Surgery is also important when patient presents with paraplegia due invasion of tumor into the spinal cord, will need decompresive laminectomy. Surgery also helps to insert Ommaya pump through which cytotoxic drug can be injected repeatedly and cerebrospinal fluid can be obtained for study. Patient with involvement of bone causing fracture may need supporting plaster cast. Patient with massive jaw tumor or thyroid tumor may need tracheostomy for obstruction of respiratory tract. The treatment of choice for $B L$ is chemotherapy. Prior to treatment with chemotherapy patient must have supportive care to prevent untoward reaction of chemotherapy. The drug of choice is cyclophosphamide. Cyclophosphamide (CPM) alone is as good as combination of CPM, Vincristine (VCR) and methotrexate (MT) in remission induction. Single dose as good as multiple dose in East African patient (73).

However the relapse free interval for 20 patients treated with sequential cyclic multiple drug combination consisting of CPM, VCR, MTX and Cytosine Arabinose (TRIKE) is significantly better than the patients who were treated with multiple dose of CPM (55).This study proves that TRIKE is better than six doses of CPM alone. Thusmaintenancetherapy is not required and in fact worsens the situation. The administration of intrathecal injection MTX with citrovorum rescue is appropriate therapy both for treatment of CNS involvement as well as prophylactic therapy to prevent the spread of disease to $\mathrm{CNS}(74,43)$.BL patients who relapse within three months, tend to be resistant to those drugs used for initial induction, but to responds to drugs not previously used: either Ara-C or a combination of either doxorubicin and CPM or doxorubicin, CPM, Ara-C and hydroxyurea and response rate is $75 \%(75)$.The high dose of CPM (2500 mg/square meter) in drug resistant tumor has shown to give objective response in four of ten patients achieving complete response suggesting that drug resistance may be relative rather than absolute (76).

$\mathrm{BL}$ is radiosensitive. However because of its peculiar cell kinetics conventional radiotherapy is ineffective (56).Prophylactic irradiation does not prevent CNS relapse and that is why prophylactic irradiation of CNS is 
not recommended (77).In BL there is convincing evidence to confirm the role of immune response in tumor surveillance. These include, inter alia: 1 . long term remission even after minimal chemotherapy, 2.occurrence of well documented spontaneous remission; and 3. humoral and cell mediated immune responses to tumor cells. The use of BCG by scarification to enhance the host immune state provoked measurable responses in vivo and in vitro.However, no measurable, specific anti-tumor reaction was observed and there is no effect on relapse rate or remission duration (78).

Treatment protocol is different for $\mathrm{BL}$ in Europe, North America and Asia. Currently treatment protocol in Asia and Europe is based on FAB LMB study which is cooperative study between the children's cancer group the societe Francoise d'Oncologe Pediatrique, and the UK Children's Cancer group or Berlin- FrankfurtMunster( $(79,80,81)$.But in North America Magrath protocol is used in almost all cases ( 82). In older studies cyclophosmamide, doxorubicin, vincristine and prednisolone (CHOP) was used with good result but high recurrence rate(83).Connors et al(84) reported $40 \%$ recurrence rate with no long term survival when treated wit MACOPB(methotrexate, doxorubicin, cyclophosphamide, vincristine, prednisone and bleomycine).In 1980s number of new regimes were introduced initially for pediatric BL. In 1986 the Stanford group (85) used CHOP like regime with intracycle high dose of methotrexate and intrathecal methotrexate to provide CNS prophylaxi Radiotheraphy was also used before after each cycle with intra-abdominal disease. The CR rate was $75 \%$ and OS rate was $67 \%$ at two years proving the fact that BL lymphoma can be cured in significant number of adults and children. Magrath et al. (82) established a protocol in North America and this protocol consists of use of: cyclophosamide, cytrabine, doxorubicin, leucovorin, methotrexate, vincristine/cytrabine, etoposide, ifosafamide, methoraxate (CODOX M/IVAC). This regimen was used in both adults and children. Four cycles are used in low risk patient and multiple cycles were used in high risk patients. Two years progression free survival was 64\%. Such protocol was used by Mead et al. (86) and confirmed very high cure rate with EFS and OS was $64.6 \%$ and $72.8 \%$ respectively. But methotrexate toxicity was high.

So modified Magrath protocol where dose of methotrexate is reduced to $3 \mathrm{~g} / \mathrm{square}$ meter of body surface area was introduced by Lacasee et al. (87). With this modified regime there was no treatment related death and complete remission response rate is $86 \%$.Smeland et al. (88) used three successive regimes for treatment of Burkitt's lymphoma at Norwegian Radium Hospital, Thromdhein, Norway. In this study $\mathrm{MmCHOP}$ was used till 1987. Then the patient who had complete remission, further treatment was consolidated with stem cell support which consists of use of MmCHOP and HDT. Then as of $1995 \mathrm{a}$ front line therapy was introduced which is called German Berlin-Frankfurt- Munster regime (BFM).BMF regime consists of combined use of fractioned cyclophosphamide, ifosfamide,high dose methotrexate(MT), with calcium folinate rescue and CNS prophylaxis with intrathecal use of MT. These three regimens are used for five to seven consecutive days with two to three weeks interval.

The conclusion of this study is that Burkitt's lymphoma can be treated with any of the three regimes both in adolescents and adults. The success rate of these three regimens, MmCHOP, MmCHOP + HDT, or BMF therapy are $30.8 \%, 70.6 \%$ and $73.3 \%$ respectively. But using BMF regimen, continuous remission is obtained without additional myloablative chemo therapy. Devine et al. (89) have used pediatric LAB protocol. Result of this study shows that two years event free survival rate and overall survival rate is $65 \%$ and $70 \%$ repectively.But this study also shows that elevated lactate dehydrogenase in patient more than 33 years age has very poor prognosis.

Ostronoff and his colleague (90) studied 46 adult cases using French Multicenter Protocols for pediatric Burkitt's lymphoma (LMB-84 and LMB-86). Kaplan -Meier 5 year relapsing free survival rate among 46 patients was $42 \%$ (stage I: $83 \%$, stage II: $67 \%$, stage: $30 \%$, and stage: $30 \%$ ).So even pediatric protocol can be used in adult patients with satisfactory result. The Japanese trial used modified LAMB protocol or 
treatment of Burkitt's lymphoma (91).Since it was a modified protocol, so this trial has used $13 \mathrm{Gm}$. of Methotrexate. I per square meter of body surface area of HD- MTX in total in addition to other chemotherapies used in LMB protocol divided into three cycles. There 56 patients in this series including three patients more than 70 years of age. All patients had complete remission including three patients older than 70 years of age. This study shows that high dose MT is tolerable in LMB protocol both in Japanese younger and older population. However such tolerability of high dose MTX is not shown in original Magarth trial. LMB protocol is also highly effective in Korean population (92).

Friedberg et al. (93) did Midline study on 470 patients with BL who has been treated for short duration with intensive chemotherapy: ALL like therapy and ACST like therapy or CHOP like therapy. In this series the median overall survival at two years was $71 \%$ and for patient's more 40 years of age was $39 \%$. This study shows even with short intensive therapy the prognosis is not satisfactory in patient's older than 40 years of age. So again the result of this study differs from that of Magrath study. There was a concern about treatment of Burkitt's lymphoma either with high dose or low dose of chemotherapy in immuno-compromised patient (HIV), such as immunodeficiency BL mostly found in North America and Europe. Oriol et al. (94) studied this topic extensively. In their series 53\% were HIV infected and treated with 6 cycles of chemotherapy and at the same time getting antiretroviral therapy with close watch on CD4 cell count. These $53 \%$ patient with HIV infection with BL had 2 years disease free survival was $82 \%$ compared to group who did not have HIV infection and 2 years disease free survival was $87 \%$.So the patient with HIV infection with concomitant $\mathrm{BL}$ can be reacted as long as retroviral treatment is not discontinued.

$\mathrm{BL}$ is notorious for over expression of CD20 which is one of the tumor markers and helps the doubling time of the tumor and enhances the tumor proliferating index. So there is great interest for using monoclonal antibody along with chemotherapy/chemotherapies to suppress the activity of CD20 and there by apoptosis of the tumor. Wasterfield and colleague (95) did study on this subject. Wasterfield group have treated 258 patients with intensive regimen such as Berlin-Frankfurt- Munster regime, CODOX-M/IVC regimen or low intensive CHOP/CHOEP regime. In this study multivariate analysis showed that addition of Rituximab was not significantly associated with improve OS. So in this study it was felt that the role Rituximab is uncertain in treating BL and needs further investigations. Similar study has been carried out by Dunleavy and colleagues (96).This group have treated19 Patients, 13 patients were HIV negative and 6 patients were HIV positive. Each group was treated with 6 cycles of DA-EPOCH-R. Each group received intrathecal MTX.OS and PFS are both $100 \%$ and $93.3 \%$ in each group. There was no case of tumor lysis syndrome. This study proves that addition of Rituximab improved OS and DFS. Barnes and his colleagues (97) have used Rituximab along with CODOX-M/IVC. Their study showed that CODOX-M/IVAC with or without Rituximab is highly effective in treatment of BL. But addition of Rituximab reduces the recurrence rate and showed a trend in favor of improvement of PFS and OS.HIV infected patients achieved outcomes comparable with those of their nonHIV infected counterparts. So the issue of Rituximab in treatment of $B L$ is unsettled. Clinician will have to use his judgment based on evidence based medicine.

The very important question always bothers the clinician/oncologist as to what to do for recurrence and the patients who are resistant therapies. Patients who respond to minimal chemotherapy responds well to aggressive treatment following relapse (69).However when there is recurrence or non-responsive to aggressive treatment then clinician should consider for autologous bone marrow transplant with full consultation with the patient and family (98).Appelbaum et al. (99) reported their experience of high dose chemotherapy followed by autologous bone marrow transplantation in 14 patients with relapse of the disease with no response to adjuvant treatment. The procedure related mortality was very high, with four early deaths. Phillips et al. (100) reported their experience in 17 patients with recurrence underwent aggressive treatment followed by autologous bone marrow transplant. These patients got partial response. Sweetnham 
et al. (101) reviewed the European Bone Marrow Transplant (EBMT) experience for recurrent of the tumor or no responders to aggressive therapies. The result in 117 patients were very modest with OS at three years was $37 \%$. Although these results are not impressive still high dose chemotherapy and autologous bone marrow transplant is the standard of care in relapsing and non-responsive disease. Weinthal et al. (102) reported a case relapsed Burkitt's lymphoma treated with unrelated with mismatched cord blood transplantation (UCBT) following salvage chemotherapy. The patient is followed for 2 years without any evidence of relapse.

Table 4. Results of selected regimens in adult BL series with at least 50 patients.

$(86,89,103,104,105,106,107)$

\begin{tabular}{lcccccc}
\hline Study & Group & N & Median age & CR & EFS & OS \\
\hline Sousain et al. (1995) & French LMB & 65 & 26 & $89 \%$ & $64 \%$ & $74 \%$ (3 years) \\
Lee et al. (2001) & CALGB & 54 & 44 & $80 \%$ & $42 \%$ est. & \\
Mead et al. (2002 & UK: CODOX-M/IVAC & 52 & 35 & $37 \%$ & $65 \%$ & $73 \%$ (2 years) \\
Rizzier et al. (2004) & CALGB 9251 & 52 & 44 & $79 \%$ & & $54 \%$ (3 years) \\
Devine et al. (2005) GELA/GEOLAMS LMB 89: 72 & 33 & $72 \%$ & $65 \%$ & $70 \%$ (2 years) \\
Thomas et al. (2006) & MDACC & 48 & 48 & $85 \%$ & $52 \%$ & $52 \%$ (3 years) \\
Hoelzer et al. (2007) & GMALL (+R) & 115 & 36 & $90 \%$ & & $91 \%$ (3 years) \\
Mead et al. (2008) & UK: CODOX-M/IVAC & 53 & 37 & $64 \%$ & $67 \%$ (2 years) \\
\hline
\end{tabular}

Future of the treatment with intent to cure Burkitt's tumor and prevention of Barkitt's tumor:

In low income countries accurate inexpensive diagnostic testing is needed. Only morphology of the tumor cannot establish the proper diagnosis of Burkitt's lymphoma. Additionally high standard of supportive care is needed prior to definite therapy. New and very effective and inexpensive therapy is needed for poor income countries. Only possibility is to use compounds with histone deacetylase inhibitor activity as adjunct treatment (108).These agents stimulate the tumor cells to differentiate and undergoes apoptosis and also induce virus lytic replication in EBV positive tumor. Tumours are more sensitive to chemotherapy when virus undergoes replication (109).With better understanding of the molecular therapy of the tumors new chemotherapy and monoclonal antibodies are being developed with better survival of patient. In 1980s Guy de described Burkitt's lymphoma as "the Rosetta stone of cancer" (110).Such description is still true now. Much is to be done to understand the Burkitt's lymphoma so that prevention of the disease as well inexpensive short term treatment will be available which will cure the patient without relapse of the disease.

\section{Acknowledgements}

The author thanks Dr. Roksana Badruddoja MBA, PhD., Dr. A .Michael Badruddoja, MD., PhD. and Frarzana Badruddoja, MS, for their advice in preparation of this manuscript. He would also like to thank Diane A. Fagen, Librarian of Crawford Memorial Medical Library of Illinois College of Medicine, Rockford Campus, Rockford, Illinois, USA for collecting the references in preparation of this manuscript. 


\section{References}

1. Smith O, Denis Parsons Burkitt CMG, MD., DSc. FRS., FRCS., FTCD (1911 93) Irish Birth, Trinity by the grace of God. B.J Hematology, 2012, 156,770-776.

2. Burkitt DP. 1958. A sarcoma involving the jaws of African Children. British J of Surgery 46, 218-223. http://dx.doi.org/10.1002/bjs.18004619704

3. Burkitt DP. 1990. The reasons for going to Africa .In: Pioneers in Pediatric Oncology (ed. Taylor) pp.39 -44. The University of Texas, MD Anderson Cancer Centre, Houston, Texas. USA.

4. O'Conner GT. 1961. Malignant Lymphoma in African Children: A pathological Entity. Cancer 14,270-284. http://dx.doi.org/10.1002/1097-0142(196103/04)14:2<270::AID-CNCR2820140207>3.0.CO;2-Q

5. Burkitt DP, O'Conner GT. 1961. MalignantLymphoma in African Children. I. A Clinical Syndrome, Cancer 14, 258269. http://dx.doi.org/10.1002/1097-0142(196103/04)14:2<258::AID-CNCR2820140206>3.0.C0;2-7

6. Editorial Comment. 2012. Nailing Burkitt Lymphoma, British $\mathrm{J}$ of Hematology 156, 780-782. http://dx.doi.org/10.1111/i.1365-2141.2012.09055.x

7. Wright, D McKeever Charter R .1997. Childhood Non-Hodgkin's Lymphomas in the United Kingdom: finding's from the UK Children's Cancer Study Group. J of Clinical Pathology 50, 12-134. http://dx.doi.org/10.1136/jcp.50.2.128

8. Swerdlow SH, Campo E, Harris NL, Jaffe E. 2008. WHO Classification of Tumor of Hemopoetic and Lymphoid Tissue, IARC, Lyon,France.

9. Smith Owen. 2012. Denis Parsons Burkitt CMG, MD., DSc. FRS., FRCS, FTCD (1911-1993) Irish by birth, trinity by the grace of God. British J Hematology 256, 770-775.

10. Nelson Cl, Temple NI. 1994. Tribute to Dennis Burkitt. Journal of Medical Biography 2, 180-183.

11. Magrath I. 2012. Epidiomelogy: Clue to the pathogenesis of Burkitt Lymphoma. British J of Hematology, 156, 744256. http://dx.doi.org/10.1111/j.1365-2141.2011.09013.x

12. Burkitt D. 1962. Determining the Climate limitationsof a children's cancer in African Children. British Medical Journal, 2 (5311), 1019-1023. http://dx.doi.org/10.1136/bmj.2.5311.1019

13. Booth K, Burkitt DP, Bassett DJ .1967. Burkitt lymphoma in Papua New Guinea. British J of Cancer 21, 657-664. http://dx.doi.org/10.1038/bjc.1967.77

14. Dalldorf G, Linsel CA, Barnhart FE. 1964. An epidemiologic approach to the lymphoma of African Children and Burkett's Sarcoma of Jaw. Prospective in Biological Medicine 7, 435-449.

15. Burkitt DP. 1962. Tumor safari in east and central Africa. Br. J Cancer 16,179-186. http://dx.doi.org/10.1038/bjc.1962.43

16. Orem J, Mbidde EK, Lambert BB. 2007. Burkitt's lymphoma in Africa, a review of epidemiology and etiology .African Health Science 7, 166-177.

17. Delhold I. Burkitt lymphoma. 2001. In Jaffe F. Harris N, Stein H et al. eds. Tissues, Washington, DC: IAC press. pp 181-184.

18. Burkitt DP. 1969. Etiology of Burkiit's lymphoma; an alternative hypothesis to a vectored virus. J Natl. Cancer Inst 42, $19-28$.

19. Herlitzka AJ, Badruddoja M, Dube V. 1973. Clinical and pathological features of Burkitt's lymphoma. Surgery Gynecology \& Obstetrics 136, 81-86.

20. World Health Organization. 1969. Histopathological definition of Burkitt's lymphoma .Bull. W.H.O 40,601-607.

21. Cardy AH, Sharp L, Little J. 2001. Burkitt's Lymphoma: A review of the epidemiology. Kuwait M J 33, 293-306.

22. Guech-Ongry M, Simard EP, Anderson AM 1971. AIDS relatedBurkitt's lymphoma in the United States: what do age and CD4 lymphocytic patterns tells us about etiology and lor biology? Blood 116, 5600-5604. http://dx.doi.org/10.1182/blood-2010-03-275917 
23. Perkins SL, Morris SW. 2007. Etiology and pathology of pediatric NHL.In: Weinstein HJ, Hudson, MM, Link MP, eds. Pediatric Lymphoma pediatric oncology, New York, Springer 7, 101-106.

24. Dave SS, Fu K, Wright GW. 2006. Molecular diagnosis of Burkitt's lymphoma. The N J Medicine 354 (23), 24312442. http://dx.doi.org/10.1056/NEJMoa055759

25. Bertrand S, Berger R, Philip T. 1981. Variant translocation in a non-endemic case of Burkitt's lymphoma t $(8 ; 22)$ in an Epstein-Barr virus -negative tumor and in a derived cell line. Eur $J$ Cancer 17, 577-584. http://dx.doi.org/10.1016/0014-2964(81)90060-8

26. Bernheim A, Berger R Lenoir G. 1981. Cytogenetic studies on African Burkitt's lymphoma cell line: t $(8 ; 14), t(2 ; 8)$ and $\mathrm{t}(8 ; 22)$ translocation. Cancer Genet Cytogenet 3(4), 307-315. http://dx.doi.org/10.1016/0165-4608(81)90039-X

27. Kaiser-McCaw B, Epstein AL, Kaplan HS. 1977. Chrosome 14 translocation in African and North American Burkitt's lymphoma 19, 482-486.

28. Shiramizu B, Barriga F, Neequaye J.1991. Patterns of chromosomal break point locations in Burkitt's lymphoma: relative to geography and Epstein -Barr virus association. Blood 77, 1515-1526.

29. Bellan C, Lazzi S, Hummel M. 2004. Immunoglobulin gene analysis of the Epstein-Barr virus and the origin of associated lymphomas. The N Eng. J Medicine 350, 1328-1337.

30. Jaffe ES, Harris NL, Stein H. 2001. World Health Organization classification of tumors: pathology and genetics of tumor of hemopoetitc and lymphoid tissues. Lyon: IARC Press,

31. Lindstrom MS, Watson KG. 2002. Role of genetic and epigenetic changes in Burkitt lymphoma. Seminar Cancer Biol 12, 381-387. http://dx.doi.org/10.1016/S1044-579X(02)00058-5

32. Dalla-Favera R, Bregani M, Erickson I. 1982I. Human c-MYC one gene located on the region of chrosome 8 that is translcocated in Burkitt lymphoma cells. Proc Natl Acad Sci USA 79, 7824-7827. http://dx.doi.org/10.1073/pnas.79.24.7824

33. Lovisa F, Mussolin, L, Corral L.2009. IGH and IGK gene rearrangements as PCR targets for pediatric lymphoma and mature B-ALL MRD analysis. Lab Invest 89, 1182-1186. http://dx.doi.org/10.1038/labinvest.2009.81

34. Nelson M, Perkins SL, Dave BJ. 2010. An increased frequency of 13 q deletion detected by fluorescence -in-situ hybridization and its impact on survival of children and adolescents with Burkkit lymphoma: Results from Children's Oncology Group. Br J Hematology148, 600-610. http://dx.doi.org/10.1111/j.1365-2141.2009.07967.x

35. Egle A, Harris AW, Bouillet P. 2004.. BOM is a suppressor of Myc-induced mouse B-cell leukemeia. Proc Nat Acad Sci USA 101, 6164-6169. http://dx.doi.org/10.1073/pnas.0401471101

36. Love C, Sun Z, Jina D. 2012.The genetic landscape of mutations in Burkitt lymphoma. Nature Science 44 (12), 1321-1327.

37. Preudhomme C, Dervite I, Wattel E. 1995. Al. Clinical significance of p53 mutation in newly diagnosed Burkitt's lymphoma and acute Lymphoblast lymphoma: A report of 48 cases. J Cl Oncology 3 (4), 812-820.

38. Richer J, Schlesner M, Hoffman S. 2012. Recurent mutation of the ID3 gene in Burkitt lymphoma identified by integrated xenome, exon and transcription sequencing. Nature Science 44(12), 1316-1322.

39. Bellan C, Lazzi S, Hummel M. 2005. Immunoglobulin gene analysis reveals 2 distinct cells of origin for EBVpositive and EBV-negative Burkitt lymphomas. Blood 106(3), 1031-1036. http://dx.doi.org/10.1182/blood-2005-01-0168

40. Kennedy G, Komano J, Sugden B. 2003. Epstein-Barr virus provides survival factor of Burkitt's lymphomas. Proc Natl Acad Sci USA 100,14269-14274. http://dx.doi.org/10.1073/pnas.2336099100

41. Burkitt DP, O'Connor GT. 1960. Malignant lymphoma in African children. Cancer 14(2), 258-269. http://dx.doi.org/10.1002/1097-0142(196103/04)14:2\%3C258::AID-CNCR2820140206\%3E3.0.CO;2-7

42. Hessling P, Molyneux E, Kamiza S. 2009. Endemic Burkitt Lymphoma: a 28 day treatment with cyclophosphamide and intrathecal methotrexate . Ann Trop Pediatrics 29, 29-34. http://dx.doi.org/10.1179/146532809X402006 
43. Ryan DP, Friedman AM, Schmitz MD. 2013. Case 11-2013: A 4 year old boy with fever and abdominal pain. The $N$ Eng J of Medicine 368, 1435-1344.

44. Mabulaiteye SM, Biggar RJ, Bhatia K. 2009. Sporadic Burkitt lymphoma incidence in the United States during 19922005. Pediatric Blood Cancer 53, 366-370. http://dx.doi.org/10.1002/pbc.22047

45. Wang S-M, Huang F-U, Wu C-H . 2010. Ileocecal Burkitt's lymphoma presenting as lleocecal Intussusception with appendecal invagination and acute appendicitis. J Formosan Medical Association 109 (6), 476-479. http://dx.doi.org/10.1016/S0929-6646(10)60080-0

46. Nkrumah FK, Perkins IV.1976. Burkitt lymphoma a clinical study of 110 patients. Cancer 37, 671-676. http://dx.doi.org/10.1002/1097-0142(197602)37:2\%3C671::AID-CNCR2820370210\%3E3.0.CO;2-D

47. Perkins AS, Friedberg JW. 2008. Burkitt lymphoma in adults. Hematology Am Soc Hematology Education Program. 341-348

48. Orem J, Katongole E and Weiderpass E. 2007. Current investigation of Burkitt's lymphoma in Africa. Tropical Doctor DI 10.1258/td..060093

49. Boerma EG, van Inhoff GW, Apple, IM et al. Gender and age related differences in Burkitt lymphoma epidemiological and clinical from the Netherlands. European J Cancer. 2004, 40: 2781-2787. http://dx.doi.org/10.1016/j.ejca.2004.09.004

50. Tesung WY, Li YW, Su U.1991. Burkitt's and non-Burkitt's Lymphoma: Clinico-pathological and radiologic manifestation. J Formosa Medical Association 90, 357- 364.

51. Karantonsi D, Jolonta H, Lowe VJ. 2010. F-FDG PET ad PET/CT in Burkitt's lymphoma. European J of Radiology 75(1), e68-e73. http://dx.doi.org/10.1016/j.ejca.2004.09.004

52. Windebank K. Lymphoma. 2004. In Bailey S, Skinner R eds. Pediatric hematology and Oncology. Oxford: Oxford University Press 443-450.

53. Carbone PP, Beard CW, Bennet JM .1969. Burkitt's tumor. Annals of Inter Medicine 70, 817-825. http://dx.doi.org/10.7326/0003-4819-70-4-817

54. Linch DC. 2012, Burkitt Lymphoma BJH, 156, 693-703.

55. Olweny CLM, Katangole-Mbodde E, Otim D. 1980. Long term experience with Burkitt's lymphoma. Int J Cancer 26, 261-266. http://dx.doi.org/10.1002/ijc.2910260302

56. Iverson $\mathrm{OH}$, Iverson U, Ziegler JL. 1974. Cell Kinetics in Burkitt's lymphoma. Eur J Cancer 10, 155-163. http://dx.doi.org/10.1016/0014-2964(74)90148-0

57. Arseneau JC, Canellos GP, Banks PM. 1975. American Burkitt's lymphoma. A clinico-pathologic study of 30 cases. I, Clinical factors relating to prolonged survival. Am J Med 58, 314-321. http://dx.doi.org/10.1016/0002-9343(75)90597-5

58. Banks PM, Arseneau JC, Gralnick HR. 1975. American Burkitt's lymphoma. A clinicopathologic of 30 cases II, Pathologic correlations. Am J Med 58, 322-329. http://dx.doi.org/10.1016/0002-9343(75)90598-7

59. Minerbrook M, Schulman P, Budman DR. 1987. Burkitt's leukemia. A re-evaluation. Cancer 49, 1444-1448. http://dx.doi.org/10.1002/1097-0142(19820401)49:7\%3C1444::AID-CNCR2820490722\%3E3.0.CO;2-C

60. Mann RB, Jaffe ES, Braylan RC. 1976. Nonendemic Burkitt's lymphoma. A B-cell tumor related to germinal center. $N$ Eng J Medicine 295, 658-691. http://dx.doi.org/10.1056/NEJM197609232951301

61. Berard GB, O'Connor GT, Thomas LB. 1969. Histopathologic definition of Burkitt's tumor. Bull WHO 40, 601-608.

62. Haralambieve E, Rosati S, van Noesel C. 2004. Florid granulomatous reaction in Epstein-Barr virus -positive nonendemic Burkitt lymphomas: a report of four cases. Am J Surg Pathol 28, 379-383. http://dx.doi.org/10.1097/00000478-200403000-00011

63. Bernhard W. 1970. Fine structure of Burkitt's lymphoma. In Burkitt DP, Wright DH (eds.): Burkitt's lymphoma. Edinburg E and S pp. 103-117. Livingstone 
64. Levine AM, Pavlova Z, Pockros AW.1983. Small noncleaved follicular center cell (FCC) lymphoma in Burkitt and non-Burkitt variants in United States. Cancer 52, 1073-1079. http://dx.doi.org/10.1002/1097-0142 (19830915)52:6\%3C1073:.: AID-CNCR2820520624\%3E3.0.CO;2-F

65. Garcia CF, Weiss LM, Warnke RA. 1986. Small nucleated cell lymphoma. An immunopheotype study of 18 cases and comparison with large cell lymphoma. Hum Pathol 17, 454-461. http://dx.doi.org/10.1016/S0046-8177 (86)80034-X

66. Haralambieva E, Boerma EJ, van Imhoff GW. 2005. Clinical, immunophenotypic, and genetic analysis of adult lymphomas with morphologic features of Burkitt lymphoma. Am J Surg Pathol 29, 1086-1094.

67. Dang CV. 1999. C-MYC target gene involved in cell growth, apoptosis, and metabolism. Mol Cell Biol 19,1-11.

68. Leoncini L, Raphael M, Stien H. 2008. Burkitt's Lymphoma. In Swerdlow SH, Campo E, Harris NI, Jaffe ES, Pileri SA, Stien H, Thiele J, Vardiman JW (eds.) : WHO classification of tumors of hemopoetic and lymphoid tissue ed. 4 Lyon, IARC Press pp. 262-264.

69. Burkitt D. 1967. Long term remission following one to two dose of chemotherapy for African Lymphoma. Cancer 20, 756-759. http://dx.doi.org/10.1002/1097-0142(1967)20:5\%3C756::AID-CNCR2820200530\%3E3.0.CO;2-P

70. Patte C, Phillip T, Rodary C. 1991. High survival rate in advanced stage B-cell lymphoma and leukemia without CNS involvement with short intensive therapy: results from the French Pediatric Oncology Society of a randomized trial of 216 children. J Clin Oncol 9, 123-132.

71. Patte C, Auperin A, Michon J. 2001. The Societe Françoise d'Oncologie Pediatrique LMB 89 protocol: highly effective multiagent chemotherapy tailored to the tumor burden and initial response in 561 unselected children with B-cell lymphomas and L3 leukemia. Blood 97, 3370-3379.

72. Reiter A, Scharppe M, Parwaresch R. 1995. Non-Hodgkin's lymphoma of childhood and adolescence: results of a treatment stratified for biologic subtypes and stage: a report of the Berlin-Frankfurt-Munster group. J Clin Oncol 13, 359-372.

73. Magrath I, Adde M, Shad A .1996. Adults and children with small non-cleaved-cell lymphoma have a similar outcome when treated with same chemotherapy regime. J Clin Oncol 14, 925-934.

70. Stovroff MC, Curan AG, Hutchinson RJ. 1991. The role of Surgery in American Burkitt's lymphoma in children. J Pediatr Surg 25, 1235-1238.

71. Philippe BC, Rao VK, Wilson WH. 2000. Burkitt 'sLymphoma: Molecular pathogenesis and treatment. Cancer Investigation 18(6), 574-583. http://dx.doi.org/10.3109/07357900009012197

72. Magarath IT, Lwanga S, Carswell W. 1974. Surgical reduction of tumor bulk in the management of abdominal Burkitt's lymphoma. Br Med J , ii: 308-312. http://dx.doi.org/10.1136/bmj.2.5914.308

73. Zigler JL, Morrow Fas L, Kyalwazi SK.1970. Treatment of Burkitt's tumor with Cyclophosmamide. Cancer 26, 474484. http://dx.doi.org/10.1002/1097-0142(197008)26:2\%3C474::AID-CNCR2820260232\%3E3.0.CO;2-A

74. Nkrumah FK, Biggar RJ, Neequaye J. 1984. Chemotherapy of Burkitt's lymphoma: Randomized clinical trial of single agent versus combination therapy. West AfrJ Med 22, 18-24.

75. Ziegler JL, Bluming AZ, Fass L .1972. Relapse patterns in Burkitt's lymphoma. Cancer Res 32, 1267-1272.

76. Nkrumah FK, Bigger RJ. 1979. High dose of cyclophosmamide in drug resistant and relapsing Burkitt's lymphoma. Ghana Med J. June, 64-67.

77. Olweny CLM, Atine I, Kaddu-Mukasa A. 1977. Cerebrospinal irradiation of Burkitt's lymphoma. Failure in preventing central nervous system relapse. Acta Radiol Ther Phys Biol 16, 225-231. http://dx.doi.org/10.3109/02841867709133941

78. Magrath IT, Ziegler JL. 1976. Failure of immunostimulation to affect the clinical course of Burkitt's lymphoma. Br Med J, 1, 615-618. http://dx.doi.org/10.1136/bmj.1.6010.615

79. Patte C, Phillip T, Rodary C. 1991. High survival rate in advanced stage B-cell lymphoma and leukemia without CNS involvement with short intensive therapy: results from the French Pediatric Oncology society of a randomized trial in 216 children. J Clin Oncol 9, 123-132. 
80. PatteC, Auperin A, Michon J. 2001. The societe Francoise d'Oncologe Pediatrique MB 89 protocol: highly effective multiagent chemotherapy tailored to the tumor burden and initial response in 561 unselected children with B-cell lymphoma and L3 leukemeia. Blood 97, 3370-3379. http://dx.doi.org/10.1182/blood.V97.11.3370

81. Reiter A, Scharppe M, Parwaresch R. 1995. Non-Hodgkin's lymphoma of childhood and adolescence: result of treatment stratified for biologic subtypes and stage-a report of the Berlin-Frankfurt-Munster group. Clin Oncol 11, 359-372.

82. Magrath I, Adde M, Shad A. 1996. Adults and children with small non-cleaved-cell lymphoma have a similar outcome when treated with same chemotherapy regime. J Clin Oncol 14, 925-934.

83. Fenaux P, Lai JL, Miaux O. 1989. Burkitt cell acute leukemia (L3 ALL) in adults a report of 18 cases. British Journal of Hematology 73, 371-376.

84. Connors JM, Khan P. 1988. MACOP-B chemotherapy in malignant lymphoma and related conditions: 1987 update and additional observations. Seminars in immunology 25, 41-46.

85. Bernstein JL, Coleman CN, Stricker JG. 1986. Combined modality therapy for adults with small noncleaved cell lymphoma (Burkitt's and non Burkitt's type). Journal of Clinical Oncology 6, 847-858.

86. Mead GM, Sydes MR, Walewski A. 2002. An international evaluation of CODOX-M and CODOX-M alternating with IVAC in adult Burkitt's lymphoma: results of United Kingdom Lymphoma Group LY06 study. Annals of Oncology 13, 1264-1274. http://dx.doi.org/10.1093/annonc/mdf253

87. Lacascc A, Hoard O, Lib S. 2004. Modified Magrath regime for adults with Burkitt and Burkitt like lymphoma: preserved efficacy with decreased toxicity. Leukemia and Lymphoma 4, 761-767. http://dx.doi.org/10.1080/1042819031000141301

88. Smeland S, Blystad AK, Kvaloy SO. 2004. Treatment of Burkitt's /Burkitt-like lymphoma in adolescents and adults: 20 year' experience from Norwegian Radium Hospital with use of three successive regimens. Annals of Oncology 15, 1072-1078. http://dx.doi.org/10.1093/annonc/mdh262

89. Divine M, Casassus P, Koscielny S. 2005. Burkitt lymphoma in adults: a prospective study of 72 patients treated with an adapted pediatric LMB protocol. Annals of Oncology 16, 1928-1935. http://dx.doi.org/10.1093/annonc/mdi403

90. Ostronoff M, Soussain C, Zambon E.1992. Burkitt's lymphoma in adults: a retrospective study of 46 cases. Hematology 34, 389-397.

91. Nishikki H, Nakamura N, Kondo Y. 2011. Treatment of adult Burkitt's lymphoma in Japanese patients with modified LMB protocol: A single center retrospective analysis. J Clin Exp Hematology 51(2), 109-114. http://dx.doi.org/10.3960/jslrt.51.109

92. Choi MK, Jun HJ, Lee SY. 2009. Treatment outcome of adult patients with Burkitt lymphoma: results using the LMB protocol in Korea. Ann Hematology Nov, 88 (11) 1099-106. doi: 10:1007/s00277-009-0729-3.E pub (Mar 14, 2009).

93. Friedberg JW, Ciminello L, Kelly J. 2005. Outcome of patients age more than 40 with Burkitt lymphoma (BL) treated with aggressive chemotherapeutic regimens: Result from the International Burkitt Lymphoma collaborative group. Blood (ASH Annual Meeting Abstract) 106, Abstract 928.

94. Oriol A, Ribera J-M, Bergua J. 2008. High dose chemotherapy and immunotherapy in adult Burkitt lymphoma. American Cancer Society, DOI 10, 1002/cncr.23522. Published online 5 May 2008.

95. Wasterfield T, Brown PN, Hageberg H. 2013. Impact of chemotherapy regimen and rituximab in adult Burkitt Iymphoma: a retrospective population based study from Nordic group. Annals of Oncology 00: 1-7. Published by Oxford University press on behalf of European Society of Medical Oncology.

96. Dunleavy K, Healey BR, Bird S. 2007. Effect and toxicity of dose -adjusted EPOCH-retixumib in adults with newly diagnosed Burkitt lymphoma. Clin Oncol ASCO Annual meeting Proceedings (post -meeting edition), 25: №: 186 (June 20 supplemental), 8035, American Society of Clinical Oncology.

97. Barnes JA, LaCasce AS, Feng Y. 2011. Evaluation of the addition of rituximab to CODOX-M/IVAC for Burkitt's lymphoma: a retrospective analysis. Annals of Oncology 22, 1859-1864. http://dx.doi.org/10.1093/annonc/mdq677 
98. Katz SJ, Lantz PM, Jantz NK. 2005. Patient involvement in surgical treatment decision for breast cancer 23(24), 5526-5533.

99. Applebaum FR, Deissorth AB, Graw Jr. RG.1978. Prolonged complete remission following high dose chemotherapy of Burkitt's lymphoma in relapse. Cancer 41, 1059-1063. http://dx.doi.org/10.1002/1097-0142(197803)41:3\%3C1059::AIDCNCR2820410339\%3E3.0.CO;2-N

100. Phillip T, Hartman O, Biron P. 1988. High dose therapy and autologous bone marrow transplantation in partial remission after first line induction therapy for diffuse non-Hodgkin's lymphoma. J Clin Oncol 7, 1118-1121.

101. Sweetenham JW, Pearce R, Tighpour G. 1996. Adult Burkitt's lymphoma and Burkitt's like non-Hodgkin's lymphoma outcome for patients treated with high-dose therapy and autologous stem cell transplantation in first remission or at relapse: results from the European group for blood and marrow transplantation, $J$ Clin Oncol 9, 2465-2472.

102. Weinthal JA, Goldman SC, Lenarsky C. 2000. Successful treatment of relapsed Burkitt's lymphoma using unrelated cord blood transplantation as a consolidation therapy. Bone Marrow Transplantation 25, 1311-1313. http://dx.doi.org/10.1038/sj.bmt.1702428

103. Soussani C, Ostronoff M, Patte C. 1995. Small non-cleaved cell lymphoma and leukemia in adults. A retrospective study of 63 adults treated with LMB pediatric protocols. Blood 3, 664-674.

104. Lee EJ, Petroni GR, Schiffer CA. 2001. Modified Magrath regimen for with Burkitt's and Burkitt's like lymphoma preserved efficacy with decreased toxicity. Leukemia and lymphoma 4, 761-767.

105. Rizziere DA, Johnson IL, Niedzwiecki D. 2004. Intensive chemotherapy with and without cranial irradiation for Burkitt leukemia and lymphoma: final results of cancer and leukemia group B study 9251. Cancer 7, 1438-1448.

106. Thomas DA, Faderl S, O'Brien S. 2006.Chemotherapy with hyper CVAD plus rituximab for treatment of adult Burkitt and Burkitt type lymphoma or acute lymphoblastic lymphoma. Cancer 7, 1569-1580. http://dx.doi.org/10.1002/cncr.21776

107. Mead GM, Barrans SL, Qian W. 2008. UK national cancer research institute lymphoma clinical studies group and Australasian leukemia and lymphoma group: A prospective clinicopathologic study of dose modified CODOX-M/IVAC in patients with sporadic Burkitt lymphoma defined using cytogenetic and immunophenotype criteria (MRCNANCRI LY10 trial). Blood 6, 248-260.

108. Simson L, Wood V, Khan O. 2009. HDAC inhibitor based therapies and hematologic malignancy. Ann Oncol 20, 1293-1302. http://dx.doi.org/10.1093/annonc/mdn792

109. Labrecque LG, Xue SA, Kazembe P.1999. Expression of Epstein-Barr virus lytically related genes in African's Burkitt's lymphoma: correlation with patient response to therapy. Int $\mathrm{J}$ Cancer 81, 6-11. http://dx.doi.org/10.1002/(SICI)1097-0215(19990331)81:1\%3C6::AID-IJC2\%3E3.0.CO;2-2

110. De The G. 1985. The Epstein-Barr virus (EBV): a Rosetta stone for understanding the role of virus in immunopathological disorders and in human carcinogenesis. Biomed Pharmacother 39, 49-51. 